\title{
An approach to designing and developing an LMS framework appropriate for young pupils
}

\author{
Radoslava Kraleva ${ }^{1}$, Mehrudin Sabani ${ }^{2}$, Velin Kralev ${ }^{3}$, Dafina Kostadinova ${ }^{4}$ \\ 1,2,3 Department of Informatics, South-West University “Neofit Rilski”, Blagoevgrad, Bulgaria \\ ${ }^{4}$ Department of Germanic and Romance Studies, South-West University “Neofit Rilski”, Blagoevgrad, Bulgaria
}

\begin{abstract}
Article Info
Article history:

Received Sep 10, 2019

Revised Oct 15, 2019

Accepted Oct 26, 2019

\section{Keywords:}

Child-computer interaction

E-learning

Learning management system

(LMS)

Software design

Software development

Software engineering

User-centered design (UCD)

ABSTRACT

The new people generation $\mathrm{Z}$ can be viewed in terms of software engineering as specific users who have high requirements regarding the functions and interface of the software applications, connectivity to social networks and instant communication via the Internet. In recent years, the number of electronic learning systems increased, but students are still not motivated to learn. This requires developing new conceptual models of training and learning software, tailored to the skills and preferences of the end-users. The young students: from kindergartens to preschools and primary schools are special users who have not been studied exhaustively. To present the problem related to the development of learning and training software thoroughly, the most commonly used standards and current trends, as well as the advantages and disadvantages of LMS platforms have been reviewed. The commonly used software design and development technologies have been discussed. We proposed a strategy for developing a web-based e-learning management system according to the possibilities of young pupils as a specific user. We described a software architecture, based on SCORM's specification, and we developed an LMS prototype. The basic methodology used in the design and creation of the system we propose is user-centered design.
\end{abstract}

Copyright $@ 2020$ Institute of Advanced Engineering and Science. All rights reserved.

\section{Corresponding Author:}

Radoslava Kraleva,

Department of Informatics,

South-West University "Neofit Rilski", Blagoevgrad, Bulgaria,

66 Ivan Michailov str, 2700 Blagoevgrad, Bulgaria,

Email: rady_kraleva@swu.bg

\section{INTRODUCTION}

In the last few years, e-learning has emerged as a promising decision for training in schools, universities, and businesses. Effective training methods are of vital importance to ensure that trainees receive the most up-to-date and accurate information. The training materials should be distributed quickly and easily, which is one of the main advantages of e-learning. A learning management system (LMS) is an integrated set of interactive web-based e-services included in a software application for the administration, documentation, tracking, reporting, and delivery of e-learning courses [1]. In other words, they are tools for teaching and learning new knowledge and skills. The purpose of e-learning environments is to promote and guide the learning process using a computer and an Internet connection [2]. They provide an opportunity for equal access to education, independent of time and place. E-learning materials can be easily updated, which determines their high relevance. Tests and e-exams are tools that impartially determine the level of learning and understanding of the learning material by trainees.

Over the last 20 years, they have become a tool for teaching and learning not only for pupils and students but also as a convenient way of teaching or training staff or self-learning. This is mainly due to the fast evolution of computer and information technology and by the growing influence of the World Wide Web 
on people's lifestyles. There are numerous examples in the scientific literature. Scientists are increasingly researching among their fellows or students to choose the most appropriate LMS; they also investigate the results achieved after using different e-learning platforms [1, 3-5].

The use of smart mobile touchscreen devices as an integral part of the modern lifestyle necessitates modifying or creating new LMSs that should meet the high requirements of modern users. The new Generation Z (people born after 1996) [6], named also the iGeneration, Gen Z, and Homelanders in the literature, prefers mostly to communicate through social networks and spend a large part of daily life in the web surfing. These young people use their smart mobile devices all the time which results in alienation, strong dependence on technology, and loss of reality view of the world [7, 8].

This, however, presupposes the emergence of new trends in software technologies and new application design which are tailored to the preferences of those new users of Generation Z. This also applies to LMS platforms. It should be noted that children are a delicate user group that has not been completely studied as other user groups [9]. Young children find it difficult to read. They are still learning fine motor skills and it is difficult to use miniature objects. They are impatient and easily lose concentration. They get bored quickly. The last few characteristics are typical for modern Generation Z.

Notwithstanding the relatively long experience of software engineers in designing and developing e-learning platforms, this problem is still interesting and relevant, especially when it relates to children in pre-school and primary school. Currently, LMS frameworks can be divided into two main groups: 1) According to price: Commercial and Free; 2) According to their use: Corporate and Education. Detailed comparisons and analyses can be found in many scientific articles as [10, 11]. But most of them are focused on the features provided by the LMS platforms, not the actual software implementation or conceptual models integrated into the software. Some scientists and developers prefer to use ready-made open-source LMS frameworks which enables them to change their interface and their features $[2,12]$. Other scientists propose methodologies for LMS developing, but without applying them to develop prototypes of such systems [13]. The disadvantage of the first ones is that the universal approach is not always suitable for the younger consumers, and the latter that without real developments, the true meaning of the proposed model cannot be verified.

Therefore, we propose a conceptual model implemented in an LMS prototype, adjusted to the capabilities and preferences of children up to 12 years-of-age. In our new approach, we take into consideration the difficulty of developing such software and explain that the general-purpose software cannot always be used by all users. Our efforts are directed to the children as users with specific skills and preferences. This issue is discussed in detail in earlier research [14, 15], where based on the analyses of children's and parents' user opinions, we identified their preferences for the interface and design and outlined the specific skills of the children. Those allowed us to design a new LMS conceptual model appropriate for children and to develop a prototype that is tailored to their skills. Thus, the discussed approach based on usercentered design is very different compared to other LMS platforms.

\section{RESEARCH METHOD}

The e-learning management systems variety is indisputable. This has been well-presented and analyzed in [11], but the need for new software applications to accommo date the capabilities and preferences of Generation $\mathrm{Z}$ children is undeniable. The software can guarantee better continuity, higher satisfaction, and longer life-cycle if it is planned, designed and developed according to the skills and preferences by the enduser. Thus, approaches based on this ideology, such as User-Centered Design (UCD), have become leading in the development of specialized software systems. Examples of applying the UCD method in LMS development can be found in [16]. The e-learning management systems usually provide several functions that can be summarized as $[11,17]$ :

- Centralized structure and easy interface navigation;

- Learning content management as thematic blocks also called modules;

- Registration of several user accounts (students, teachers, parents, administrators);

- Presentation and access to various multimedia resources called also learning objects;

- Assessment of the achieved results by the students;

- Individual tracking of activities, development and progress of the student in the training course;

- Tool for communication between users;

- Help system providing information about the use of the platform;

- Reliability and security of the stored data;

- Reuse of the learning objects;

- System administration.

The items in the list above are the functions that every LMS platform should have. 


\subsection{Advantages and disadvantages of e-learning environments}

The advantages and disadvantages of e-learning have been the subject of research over the relatively long stage of its development and implementation [18-22]. Therefore, in this section, they will be only briefly discussed.

Some of the advantages of e-learning can be summarized as [18]:

- E-learning is independent of the time and place;

- E-learning delivers high-quality training without traveling;

- E-learning has a low cost;

- Filtering and adapting course content;

- Lack of a strict schedule;

- Easy updating of learning contents;

- Tracking tool of all activities and current progress, both by the trainees themselves and by their trainers;

- Providing tools for building and maintaining interactive multimedia content.

Even with all these advantages of e-learning, there are some disadvantages. For example, some practical skills are more difficult to study in e-environment. Some of the disadvantages of e-learning are $[18,22]$ :

- Teachers must have good knowledge and skills in information technology;

- E-learning requires more effort and self-discipline by the trainees;

- There is social isolation between trainees and between trainees-teachers;

- There are health risks: E-learning requires the use of computer devices, leading to eye problems, bad posture, and/or other illnesses.

\subsection{Standards and trends in e-learning}

Interdisciplinary specialists, such as designers, programmers, educators, psychologists, take part in the development of e-learning management systems. If clear standards and accurate software specifications that the LMS platform must match lack, managing and developing such a project will be a difficult and expensive task. One of the main goals of the standardization process is to save resources, time and effort. E-learning standards are a set of common rules that should be applied to the learning content development, the e-learning software applications development, and the LMS platform development. They provide all parties with guidance on the design and development of e-learning content, requirements to the LMS platforms, and interoperability across devices [23]. For [24], the most important purpose of learning standards can be divided into several categories: Metadata; Content packaging; Learner profile; Learner registration; Content communication. In this section, only two standards are discussed: content design standards relating to various aspects of designing and developing e-learning content and technical standards, related to the development of LMS platforms.

a) E-learning content design standard

E-learning content design standard includes instruction design, visual design standards, multimedia objects, texts, and assessment methods [17, 24, 25]. E-course instruction development standards help developers to define the goals and strategies of its content, the interactivity degree, the assessment methods, and the ways of communication between trainees and trainers. Bloom's taxonomy [26] is one of the first guides to develop a logical content framework for e-learning. Visual design standards are rules for the graphical user interface (GUI) and its navigation elements. The interface elements for navigation in the e-course should be intuitive and easy to use. The purpose of visual design standards is to ensure design integrity between lessons and modules. Multimedia object standards provide consistency and compatibility in multimedia objects used in the e-course contents, such as screen layout/size, text elements, graphics, animation, audio, and video. The use of multimedia standards depends on the end-users. Text standards determine the text content design and organization in an e-learning platform. Specific written standards are used here to determine the used language, punctuation, lists, abbreviations, acronyms, and other text elements. The standards of assessment should align with the learning goals. They determine the method of students' evaluation during and after completing the course.

b) E-leaning technical standards

The technical standards refer to the functionality and portability of e-learning courses across devices, browsers, and operating systems. Some of the most frequently used technical standards are SCORM, xAPI, CMI5, and AICC [24, 27, 28].

- SCORM (Shareable Content Object Reference Model) [29-31]: This technical standard is developed by the United States Department of Defense, Advanced Distributed Learning (ADL) group. SCORM unify the structure of eLearning so that learning objects and assets (images, video, documents, webpages) could be reused and transferred between systems, military departments, and remote locations [30]. According to 
this standard, every LMS system should be a centralized e-learning system with a high-level of stored data security.

- $x A P I$ (Experience API) [31]: The xAPI is a new specification standard for e-learning systems that makes possible the collection of data from a wide range of learner activities. The data is recorded in the Learning Record Store (LRS) and can be shared with other LRS systems. This standard is based on the people abilities to learn constantly, whether he or she is communicating with other people on the web, reading news blocks, or searching for some information.

- CMI5 [28]: CMI5 is a modern e-learning standard. It uses the definition of the xAPI standard with interoperability determined between different systems.

- AICC (Aviation Industry Computer-Based Training Committee) [27]: This technical standard was created for e-learning for airlines staff. Although the purpose of the AICC standard is the same as that of SCORM, the difference is that it uses HTTP messages to communicate between the LMS components. Due to the complexity of the AICC, this standard is not widespread [32].

c) Trends in modern e-learning

There are lots of technical tools that support the process of interactive courses development, the learning process standardization, and adding non-formal elements to the learning process. There are several trends in modern e-learning that can be defined as follows:

- Micro-learning or Micro-eLearning education: It focuses on activities in the complex educational process divided into small chunks, called micro-contents. Often it is achieved with short multimedia objects that do not last more than a few minutes [33, 34]. Unlike the 'traditional' approaches to e-learning, microlearning reduces the amount of knowledge that should be learned. As the learning material is divided into micro-contents, this learning is suitable to use as part of mobile learning [35].

- Gamification is the use of game strategic thinking in a non-game context to solve various tasks [36]. This is a relatively new approach in education, but more and more scholars are seeing increased students' interest as a result of its use [37]. The essential gamification elements are competition, rewards, collecting points, and group work. They are used successfully in e-learning. After the students complete a learning activity, they usually receive a reward.

- Virtual reality (VR) and Augmented reality (AR): Currently, they are the most popular training innovations [38]. Virtual reality has been around for a long time. However, they provide an opportunity for accessible acquisition of new knowledge and skills in complex disciplines such as medicine, architecture, etc. [39]. This is due to the various simulations that provide realistic visualization of objects, organisms, places, and situations, and allow for easier learning in a safe virtual environment.

- Automatic conversational system and Chatbot [40]: The use of chatbots is widespread in various areas, such as marketing research, e-commerce sites or booking platforms. They use sophisticated natural language processing algorithms to answer intelligently to a user question. There are lots of science works presenting the positive impact of electronic assistants in the e-learning [41, 42]. This smart tool helps the students to ask questions and receive smart answers at any time of the day.

- Adaptive e-learning: Adaptive learning is characterized by personalization of existing learning objects according to the preference of every user [43]. The biggest advantage of this learning is that the trainee/student does not need to go through the full e-course. Instead, focused training is provided based on various methodologies to determine the amount of learning and gaps in the learner's knowledge. The questionnaires and algorithms (statistical or artificial neural networks), such as the methods discussed in [44], that determine what is needed to educate a particular user, are often used [45].

- Video-based e-learning [46]: The popularity of video lessons on YouTube and other online video database services continues to increase. Interactive videos are different from them, and they often have diverging scenarios. The benefit of this method is that trainees engage and spend more time and effort into the learning process. Furthermore, they considered the video-based e-learning approach useful because it allows them to control their pace, time and location for learning [47].

- Social learning: When learning is spread and shared among peers, the educational process improves. Some scientists think that social media such as blogs, wikis, Skype or Google Hangouts, Facebook, WhatsApp could support learning and the creation of knowledge in e-learning environments [48, 49].

\subsection{Methods used for designing and development}

Based on the reviewed literature sources and the current web application development technologies, it can be concluded that there cannot be a right or wrong choice for a programming language or an integrated development environment for LMS platform development. Most often, the choice is influenced by the individual skills and preferences of the developers. The main approach used in developing this platform is Use-centered design (UCD). According to its theory, the development of any software should be userfriendly. There are two ways to collect consumers' opinion. The first way is to conduct a survey among 
the relevant user group. The questionnaires used should contain short and precise answers and their results should be used in software design and development processes. The second way is to ask a small group of users to participate in the design and development process.

We used both approaches, i.e. a survey was conducted, and children participated in the development of the prototype of the LMS presented in this article. This extended the process of designing the conceptual model and the process of developing the prototype but gave a clearer idea of the preferences of the users themselves, i.e., the pupils being trained. This differs significantly from the design and development approach for the LMS platform discussed in this article from all the other approaches discussed in the literature.

We made a short electronic questionnaire consisting of 10 questions, which included 52 children and young people from Bulgarian schools, aged 7 to 18 years, including 27 girls and 25 boys. About $81 \%$ of the surveyed individuals indicated that they were more motivated to learn when using interactive electronic materials available from any mobile computing device, such as a laptop, tablet, smartphone. When asked "What would you prefer to use during your e-learning?", the most of the surveyed $(71.2 \%)$ said "E-learning games with rewards and points accumulation" followed by "Video Tutorials" $(67.3 \%)$ and the lowest percentage $(26.9 \%)$ indicated "Electronic Readable Lessons". Not surprisingly, $82.7 \%$ of all respondents indicated that they were stressed during the exam; more than $90 \%$ of all preferred the written exam, with $60 \%$ preferring to use tests as a way of checking of knowledge. The other questions in the survey were related to the computer literacy of the students and they answered all the questions only in the affirmative. The survey made decide that the developed prototype should have an adaptive interface in order to be compatible with all mobile computing devices. During the design of the conceptual model and the development of the interface of the discussed LMS, 3 persons aged 12, 14 and 18 participated. They came up with ideas and criticized our proposals. This is the second approach used by the UCD theory, which allows us to argue that the proposed model is fully consistent with the preferences and capabilities of students who are the real users of the system.

No science work presenting the use of both a user opinion survey and user participation in the LMS design and development approach was found during the study. For the back-end development of our LMS prototype the PHP programming language is used, and for database management system the MySQL is used. The reasons for our decision are: popularity, stability, reliability, speed and price. To design the user interface, we used HTML and CSS. We used a few integrated development environments: Microsoft Visual Studio (for managing HTML and CSS), Atom (for managing PHP code), XAMPP (for managing a local webserver). Graphic images are needed to build a beautiful user interface. Many of the images used in our interface design were created with Inkscape (an Open Source vector graphics editor) and GIMP (a crossplatform image editor). Other files were downloaded from the websites with a free license for commercial use: pixabay.com, kisspng.com, unsplash.com.

\section{RESULTS AND ANALYSIS}

As a result of our study, a conceptual model of a web-based e-learning management system was developed. We used this model to create a prototype of an LMS platform, called "My classroom". According to [45] all e-Learning Management Systems follow a very similar integration and development process. This is true about our proposed model.

The used process contends eight interconnected steps as shown in Figure 1:

a) Requirements: The requirements for the hardware configuration of the web server and the development software are defined. The function requirements that the LMS platform must perform and their suitability for the specific group of users are described.

b) Need storage data: The requirements for the stored data in the database are determined.

c) Learning management system specification: Using natural language or through UML notation, a unique specification that determines the requirements to software is formulated.

d) Interface design: In the fifth step, the software product interface must be designed.

e) Database design: A relational database based on the data requirements to be stored, processed and used should be designed.

f) Development of LMS: Based on the proposed software specification and the designed interface templates, and according to the interaction between interface elements and data, a MySQL relational database is developed, and an LMS framework is coded.

g) LMS testing: Testing is divided into two stages - internal testing and independent testing. In internal testing, the software is subjected to numerous tests related to system security, data security, and software reliability. External testing refers to software testing in a real work environment, i.e., it will be 
implemented in a school/university. The users should use the software for a certain time. This contributes to timely debugging and removing possible systemic problems.

h) LMS implementation: This stage is related to the installation and use of the system in a real work environment. This process involves collecting the opinions of students, teachers, and parents. The obtained data are analyzed, and a decision, based on the results for the future development of the system is made.

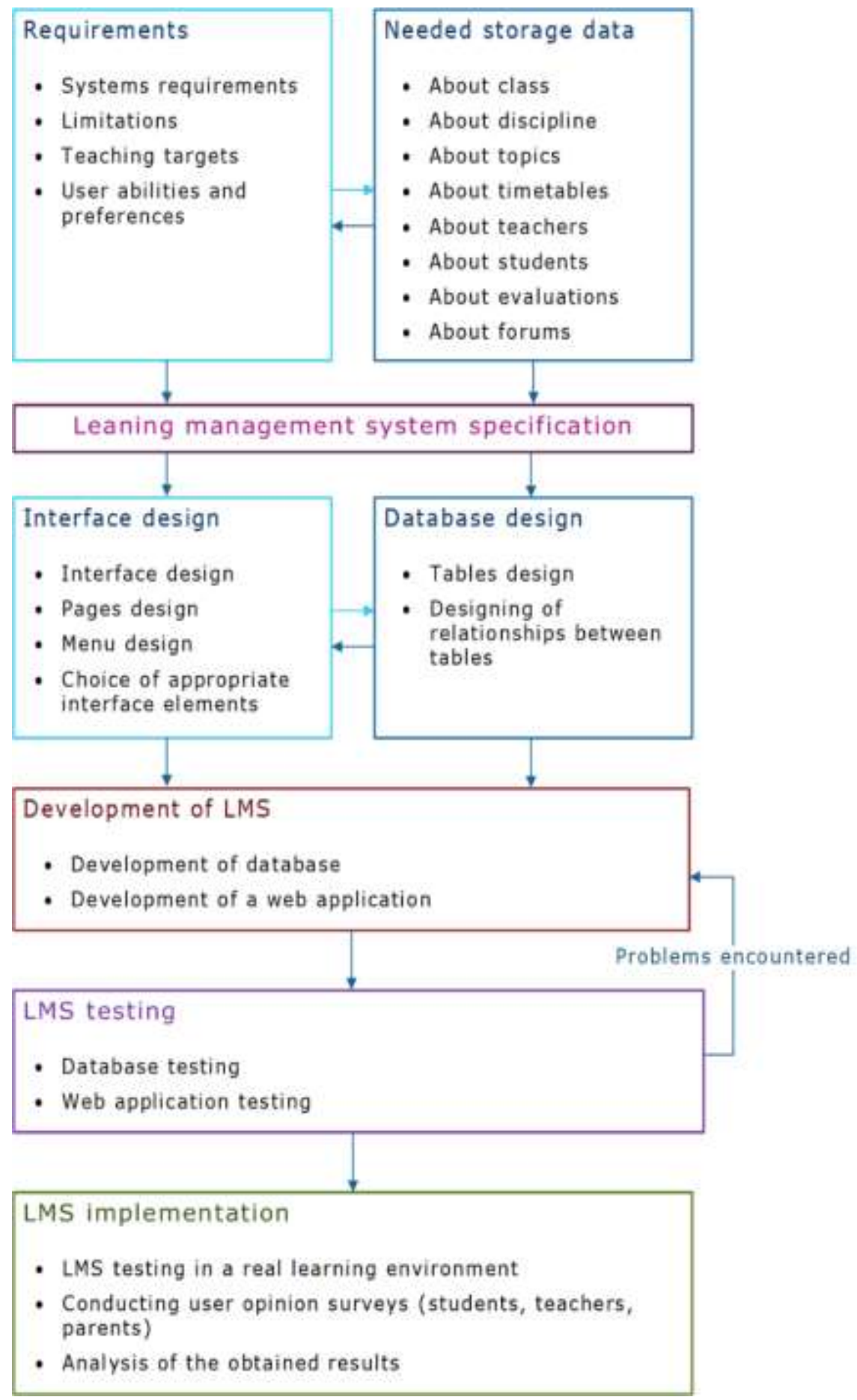

Figure 1. Approach to development of an LMS framework 
Stages 1, 2 and 3 were discussed in our previous studies [11, 15] and we will not discuss them here. The database corresponds to databases in other LMS platforms. Hence, we will not discuss stage 5. A particular interest is the architectural model and the developed design of an LMS platform which will be discussed in detail in this article.

\subsection{Software architectural model}

The software architectural model represents the interconnections and the relationships between the modules (forms) of a software application. Our system is aimed at pre-primary and primary school children and should provide an intuitive and easy-to-use interface. The proposed architectural model is based on various user roles that can use an LMS system. On this basis, the possible functions of the system are determined. Therefore, the architectural model depends on both the users and the features that the software offers. Four types of user roles are considered: administrator, teacher, student, and guest.

The administrator has full rights to the system, the user accounts, and its content. He/she can approve or create every new account. Once a new user account is created, whether it is done by an administrator or by a user, the responsibility of an administrator is to determine the role of this new user. Then the user account will have different privileges according to his/her user role. The proposed system needs an administrator with computer knowledge and skills in web application development. Then he/she will be able to develop and add new learning games. All the fun additions will be available from the Play and Learn page. Also, the administrator takes responsibility for making and maintaining the learning schedule.

The teacher user account allows reviewing all students registered in the teacher-led course. He/she should be able to create, edit and delete e-courses, topics and assignments (homework and course projects). $\mathrm{He} / \mathrm{she}$ should be able to register students and approve their registration requirements for his/her courses. $\mathrm{He} / \mathrm{she}$ should be able to determine the methods of assessment, create urns with questions from which the system will automatically generate tests, to hide or display these tests. The teacher should able to create additional learning activities, such as visits to museums/theatres, supporting the learning process. These activities will display in the School Activities module. Also, the teacher should able to track the time that the students used the LMS platform and all their activities. Then the teacher can understand which teaching materials are frequently read, what the mistakes of the students are, and which education materials should be repeated to minimize the possible mistakes. This is especially important for dual learning, which is the most commonly used in Bulgaria.

The guest user account is used in many web systems. It is characterized by open access and limited capabilities. When the homepage of the LMS platform is started, the guest account should allow browsing the help system, viewing the authors' page, the current schedule and calendar from School Activities page, browsing the available games from Play and Learn page, contact information for the teachers and courses from the Contact page. The user with a guest account can create a new student account, using the "Join" button which launches the page creating new accounts. This registration should be approved by the system administrator.

The Manage Class module should be accessible to the teacher account and administrator account. The teacher will only be able to view the registered students in the e-course or to register those students who have submitted a request. The administrator can manage all e-classes and register user to them. $\mathrm{He} / \mathrm{she}$ is responsible for the data security and the rights to access it.

In the Study assignment module, the teacher should be able to add new homework, coursework, or other learning tasks. The data related to them are a start date and end date for the performance, a topic, and a detailed description. All assigned tasks should be visible for all students registered in the relevant e-course. Each task can be seen on the Calendar page, and it is marked in special colour. For example, if a task is not completed on time, i.e., the student did not answer until to the end date, its cell on the calendar will colour in red. If this happens, the teacher has the right to extend the deadline or set a new task only for a student or group of students. This will be an advantage for all students who attend extra classes for a subject and can independently develop additional tasks other than those in the compulsory e-class. Settings can be used to make changes to the account settings, such as design template choice and changing interface language.

The following features are available on the My Profile page: user data, courses completed, study activities completed, written forum comments, assessments (only for the student account). The Forum module is a group social network in which students and teachers can easily communicate with each other, discuss learning materials, and solve tasks together. Each forum topic can be opened (visible) or closed (hidden), according to the author's preferences. The forum is a very important tool for every modern e-learning management system. The proposed architectural model of an LMS platform is presented in Figure 2. 


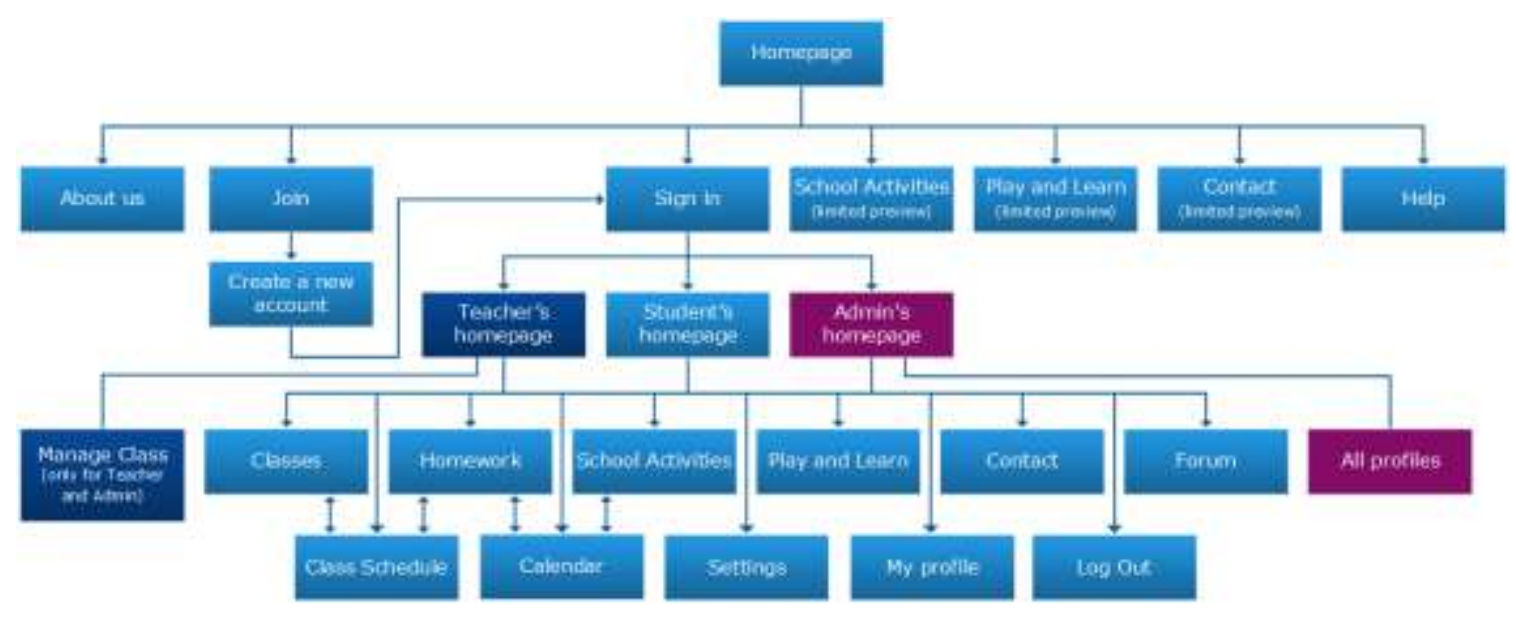

Figure 2. Architectural model of LMS

\subsection{Design of an LMS framework}

Based on the described software architectural model, the design of a developed e-learning management platform, called "My classroom", will be presented in this section. Currently, the software is being tested in one primary school and it is still not available on the Web.

Some of the more important features of the developed platform are:

- Four types of user accounts are supported - guest, student, teacher and administrator [14]. Guest is a nonregistered user who has the most restricted access. Students are registered users who can view, download learning material, and post comments on the forum. Teachers are registered users, who can create and edit e-courses; upload, edit and delete learning materials (lectures, exercises, assignments); create, edit, and delete new topics in the forum; and answer students' questions and comments. Only the administrator account has full rights to access all the functionality of our LMS. He/she can create, edit, and delete users' profiles; create and delete e-courses; create, remove, and edit all topics and comments in a forum, i.e., he/she can manage all system.

- It supports various file formats as a tool for building an e-course and related learning materials.

- It provides tools for communication between users of the system: forum and e-mail server.

- It provides a tool to create and evaluate tests.

- It provides a calendar scheduling tool presenting all important events, such as dates for tests, holidays, excursions, etc.

- It provides a tool for creating and managing a curriculum based on a study presented in [50].

- It has a responsive web design for a smartphone and tablet, according to previous studies, presented in [15].

When "My classroom" platform is started, the Homepage is loaded as shown in Figure 3. In the central part of the window, six big buttons are available, and they form the main menu of the system. These buttons contain a text and an image. In the top right corner of the window, there are two small buttons - "Join" and "Sign in". They allow creating a new user account ("Join" button) or login into the system ("Sign in" button).

Figure 3 shows the difference between the Homepage of a teacher account and the same page of a student account. A side menu that opens after login to the system offers additional settings and applications to the user. In case the user has a teacher account, he/she can use six sub-menus: "My Profile", "Manage Class", "Calendar", "Class Schedule", "Notifications", and "Settings". If the user has a student account, the "Manage Class" sub-menu is missing. The Manage Class page allows the teacher to manage students' data registered in his/her e-class.

The Calendar page allows teachers and administrators to enter, edit, and delete events (school activities and tasks) data that students and guests of the system can view. They cannot make any changes or create new ones. The names of all months previous and next year are presented as buttons on the top of the Calendar page. They are used to navigate in the calendar and view all learning events. Today's date is coloured in blue, the important events are coloured in yellow, overdue are coloured in red, and other dates are coloured in grey. The main feature of this page is to manage and to organize important events. To create a new event, the user must click on the desired date, and then a new window will open in which he/she must 
enter the required event data. An example of a math test event, created by a teacher, is shown in Figure 4. The "Class Schedule" button in the side menu opens the module for organizing and maintaining the schedule for all courses for which training is provided. The design of this page is presented in Figure 4.

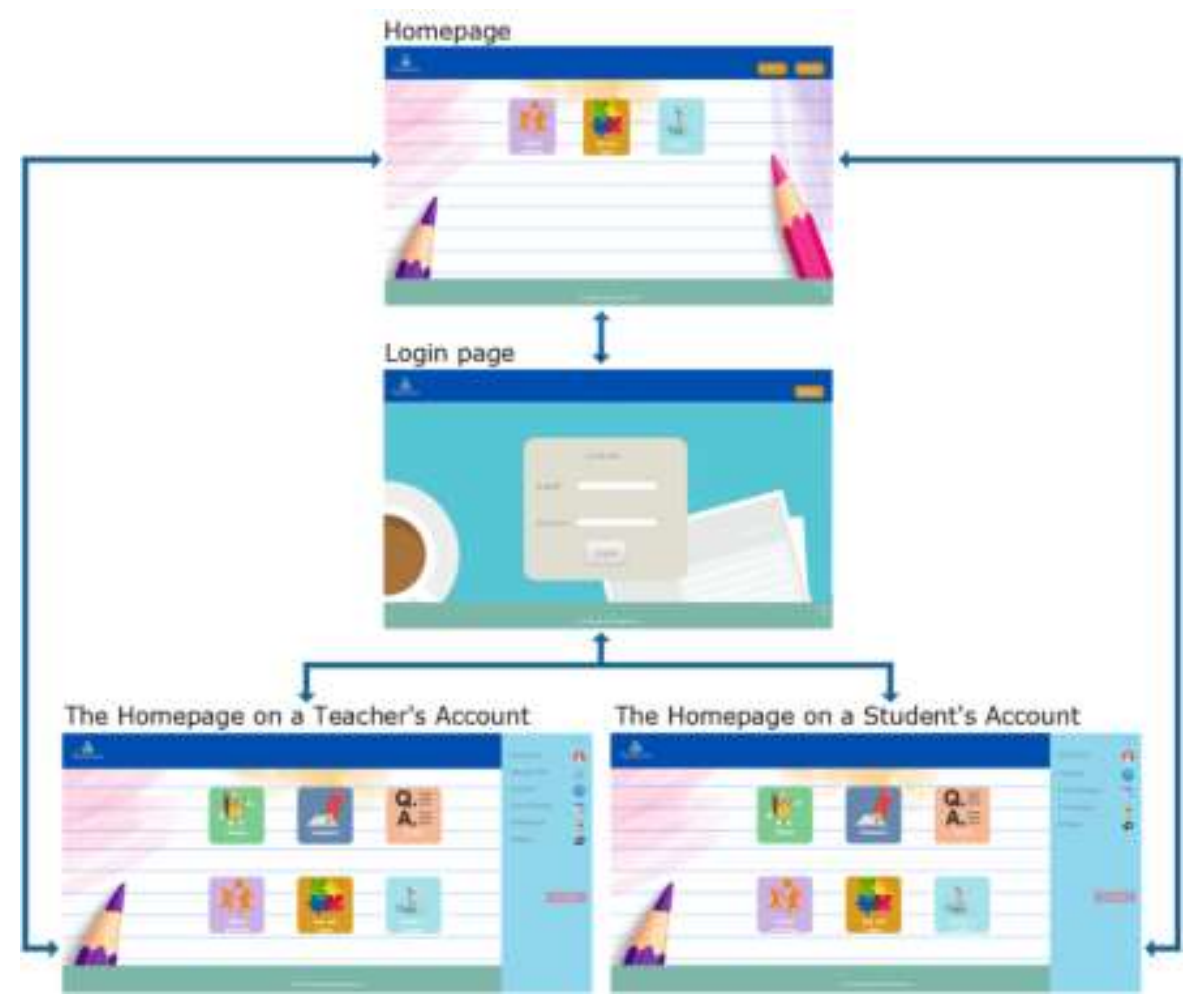

Figure 3. Homepage and login page on "My classroom" LMS
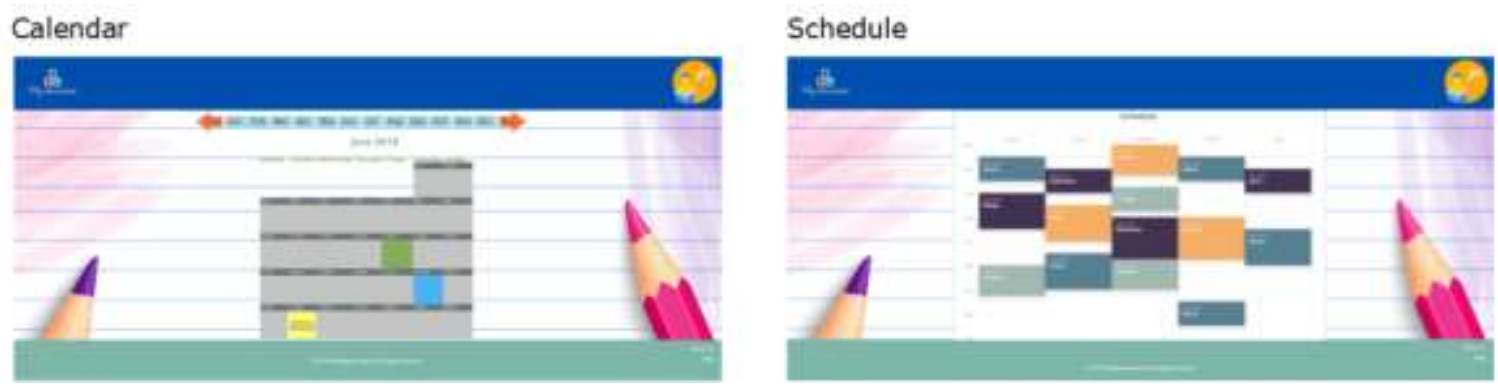

Figure 4. Design of the calendar and schedule

The "Classes" submenu provides all the tools related to creating, editing, managing, and deleting the courses, lessons, homework, and additional learning materials. After clicking "Classes", the "My Classes" page loads. It contains additional submenus for each e-class. For example, let us select the Grammar course as shown in Figure 5 which uploads a page for new lessons in text format (pdf, txt, doc, HTML) and/or video format is loaded. The teacher can edit, add, delete while the student can only view the uploaded information.

A lesson template at our LMS platform is presented in Figure 5. The Homework submenu provides two options, a homework creation page and tests creation application. Currently, the tests that can be done with our LMS platform are only closed-ended with four possible answers. After the student completes a test, he/she receives a certain number of points, based on the number of points for every correct answer, which is graded on a scale pre-determined by the teacher. This assessment appears at the end of the test and is also added to the learner's profile. 
The "Forum" submenu as shown in Figue 6 leads to a module whose primary role is to provide communication between teachers and students. For its normal work, it uses four tables from the database: "categories", "subcategories", "replies" and "topics". The first forum page is divided into two components: "add new topic" - to add a new topic in the forum and "homework problem" - access to the earlier asked questions related to a selected topic. It has four pre-created sample topics: "Homework", "Field Trip", "Subjects", "Other". Additional topics and subtopics can be added by the administrator or teacher.

To add a question to the forum, the student should select one of the topics, as he/she cannot create a new topic as shown in Figure 6. The component containing the questions already asked shows the question title, the user's name, who posted it, date of posting, number of views, and number of replies. Clicking on the title of an already created post opens the question in the post. The "Add new topic" button opens a page for asking questions as shown in Figure 6.

The "School Activities" submenu opens the page in which the teacher can publish additional articles and news. The page uses data from the "news" relational table. The required input data are title and subject texts. The "Play and Learn" submenu is designed similarly to the previous submenu and leads to educational games. The data is recorded in the "games" table. The "Contact a teacher" page contains contact information: e-mail, phone number and the teachers' names and support staff. The data is recorded in the "contact" table.

We used a responsive web design for the front-end development for our e-learning system. The platform has an adaptive design that is compatible with mobile computing devices such as tablets and smartphones. Thus, when a user loads the system on his mobile device, the interface elements on every page will automatically adapt to use it easily on a small screen. The buttons will get bigger, the contrast of the text will be stronger, and the less important elements will be removed or reduced. A homepage view on the "My classroom" LMS platform in a mobile web browser is presented in Figure 7.

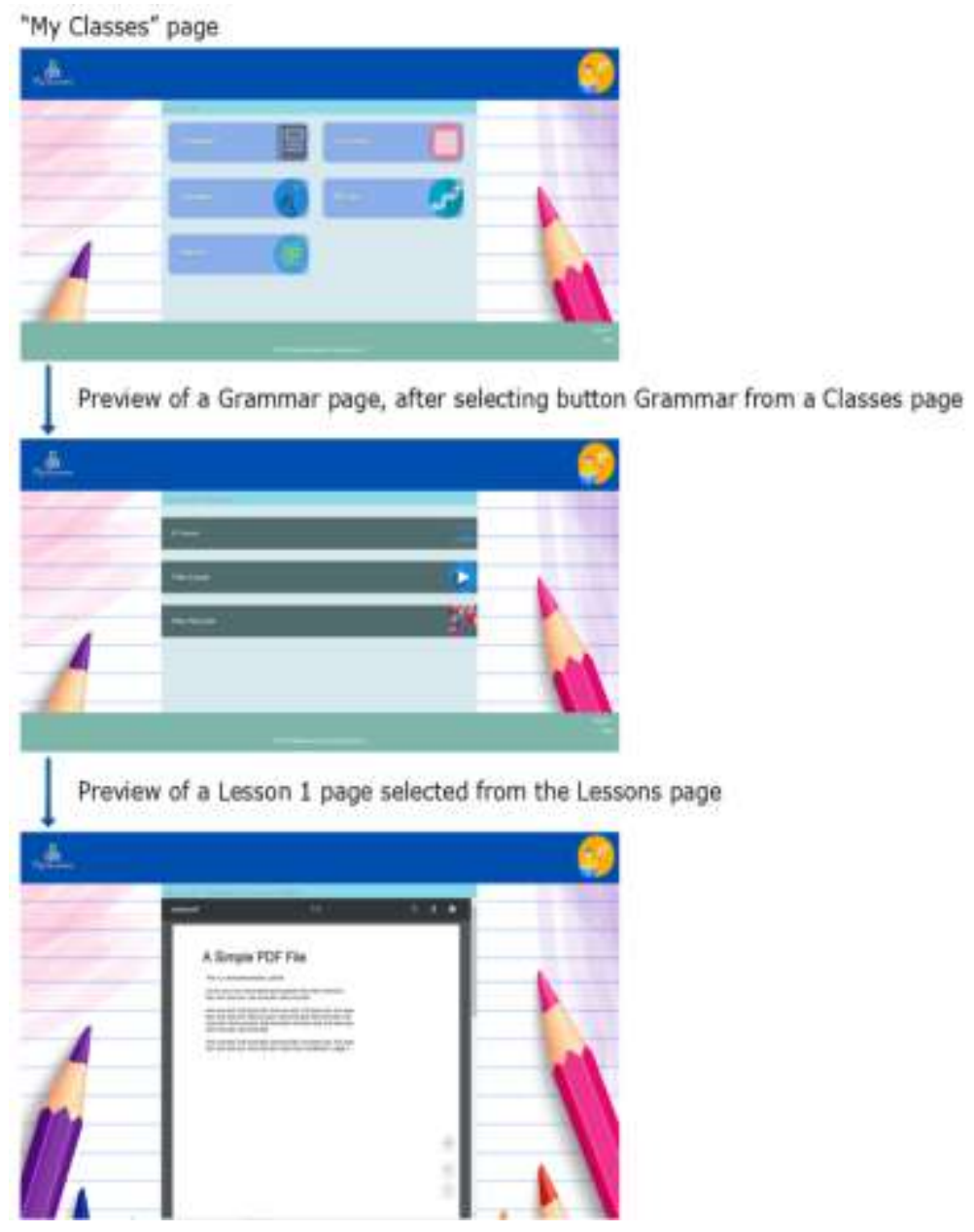

Figure 5. Design of "My Classes" page, a course page, and lesson page 


\section{Forum homepage}

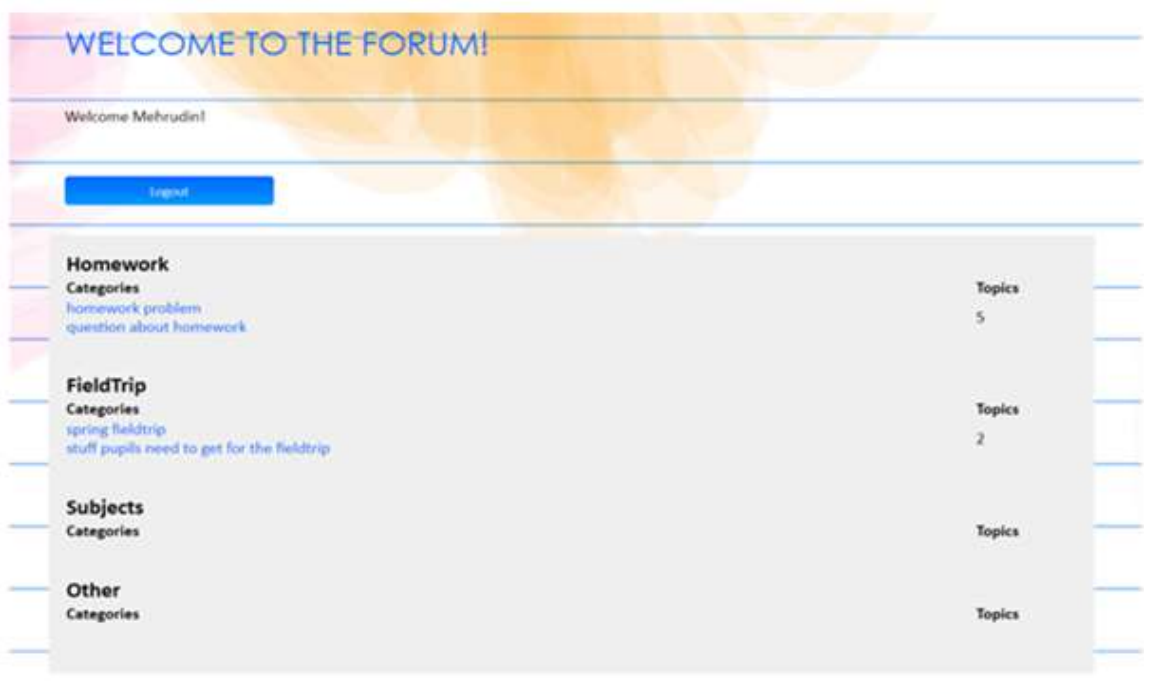

A page containing all topics in the Forum

\begin{tabular}{|c|c|c|c|c|}
\hline Welcome Mehrudin! & View Toples & & & \\
\hline \multicolumn{5}{|l|}{ than } \\
\hline \multicolumn{5}{|l|}{ add new topic: } \\
\hline Tive & Ponted by & Date Ponted & Views & Replies \\
\hline Eammar. & Mehrudin & $2019.06-08$ & 64 & 3 \\
\hline this is a test topic & wer1 & $2019-06-08$ & 65 & 1 \\
\hline mathe & Mehrudin & $2019-06-08$ & 16 & 1 \\
\hline muth & Metrudin & $2019-06-08$ & 2 & 0 \\
\hline mathe & Metrudin & $201906-08$ & 10 & 0 \\
\hline
\end{tabular}

A page for creating a new post in the forum

WELCOME TO THE FORUM!

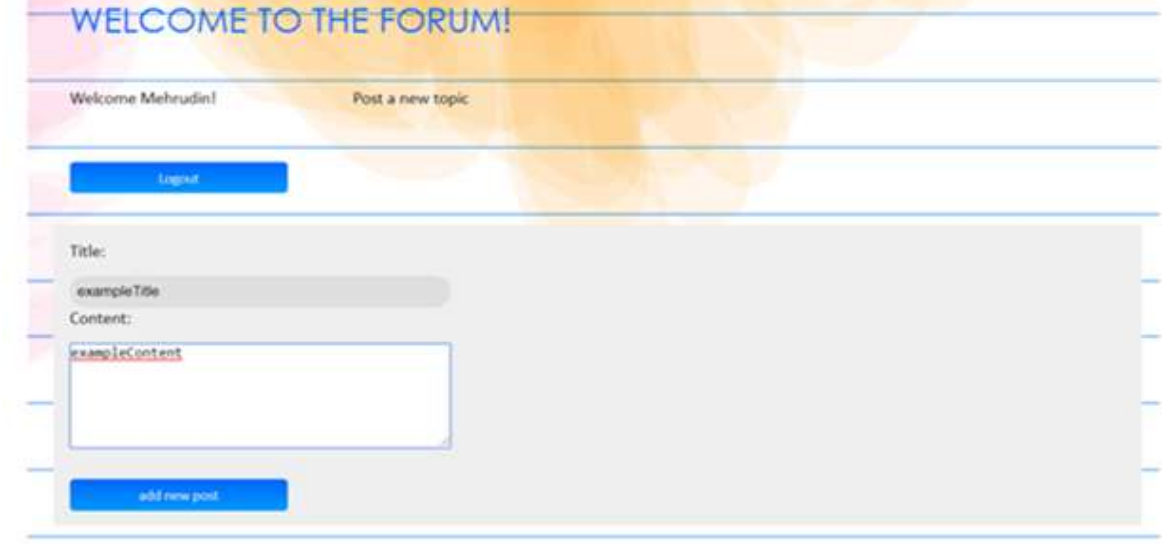

Figure 6. Forum module 


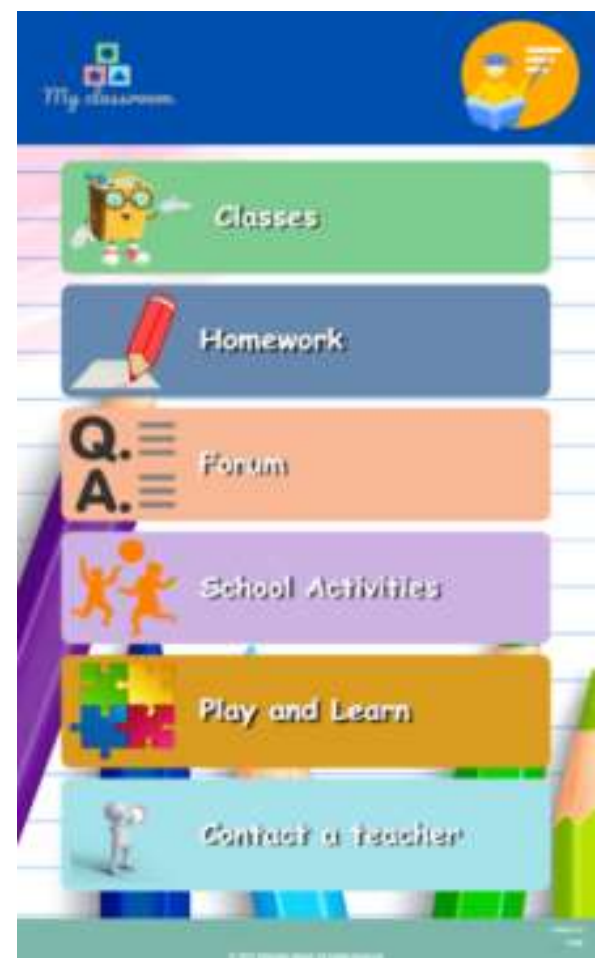

Figure 7. The "My classroom" LMS platform in a mobile web browser

\section{CONCLUSION}

End users are the factor determining the lifecycle of a software product. However, their preferences change over time and depend on some factors such as age, gender, social status, and life experience. Currently, the users belong to Generation $\mathrm{Z}$ and depend directly on the Internet and all computer and information technology. Software applications, programming languages, and computer devices have undergone some evolutionary changes and are continually evolving and upgrading to meet the high expectations of users. This also pertains to software, designed for young children up to 12 years. The development of software intended for teaching children or as a tool for assisting this process must meet the current trends and be appropriate to their skills. Designing and developing modern software with an easy and flexible user interface that improves the motivation and the interest of children to learning is not an easy task at all. Therefore, the main purpose of this article was to offer a conceptual model of an LMS platform that completely satisfies and matches the skills of young users. The basic methodology used in the design and development of our software is user-centered design.

The proposed model was developed based on research and analysis of contemporary literary sources, and on previous studies by the authors of this article. To validation of the approach designing and developing an LMS framework, a demo version of an e-learning management system was developed. The software supports four kinds of users: administrators, teachers, students, and guests. It maintains creating and updating e-learning materials, managing students' data, test system, forum and data securities. The interface is tailored to the motor skills of children up to 12 years by selecting appropriate colour combinations, easy-to-read fonts, and simple images. From a design view, all the confusing and complicated menus and submenus are reduced to minimum. Parents are a very important part of children's education. And as such, they must also be involved in this process and they should have access to the LMS platforms used by their children. Currently, the parents can use "My classroom" software only via the child's profile. But we plan to add the option for a parent account in the next version of the system. At the time of writing this article, the proposed software is subjected to verification by pupils in a primary school. Monthly questionnaires are planned to test the knowledge and skills of children who use the system to verify their satisfaction with the software product they receive. 


\section{REFERENCES}

[1] C. Ardito, M. F. Costabile, M. De Marsico, R. Lanzilotti, S. Levialdi, T. Roselli, and V. Rossano, "An approach to usability evaluation of e-learning applications," Universal access in the information society, vol. 4, no. 3, pp. 270-283, 2006.

[2] H. J. Chang, K. Symkhampha, K. H. Huh, W. J. Yi, M. S. Heo, S. S. Lee, and S. C. Choi, "The development of a learning management system for dental radiology education: A technical report," Imaging science in dentistry, vol. 47 , no. 1 , pp. $51-55,2017$.

[3] M. White and T. Shellenbarger, "Harnessing the power of learning management systems: An E-learning approach for professional development," Journal for nurses in professional development, vol. 33, no. 3, pp. 138-141, 2017.

[4] S. Macnaughton, M. Medinsky, "Staff training, onboarding, and professional development using a learning management system," Partnership: The Canadian Journal of Library and Information Practice and Research, vol. 10, no. 2, 2015.

[5] G. Veletsianos, (Ed.) "Emergence and innovation in digital learning: Foundations and applications," Athabasca University Press, 2016.

[6] M. Dimock, "Defining generations: Where Millennials end and Generation Z begins," Pew Research Center, 2019. Available: http://tony-silva.com/eslefl/miscstudent/downloadpagearticles/defgenerations-pew.pdf [Accessed: Sep 2, 2019].

[7] A. Tick, "Research on the Digital Learning and E-learning Behaviour and Habits of the Early Z Generation," in 2018 IEEE 22nd International Conference on Intelligent Engineering Systems (INES), IEEE, pp. 000033-000038, June, 2018.

[8] C. Seemiller and M. Grace, "Generation Z: Educating and engaging the next generation of students," About Campus, vol. 22, no. 3, pp. 21-26, 2017.

[9] M. K. Sabariah, P. I. Santosa, and R. Ferdiana, "Requirement Elicitation Framework for Child Learning Application-A Research Plan". in proc. of 2nd International Conference on Software Engineering and Information Management 2019, ACM, pp. 129-133, January, 2019.

[10] D. McIntosh, "Vendors of learning management and eLearning products," Trimeritus eLearning Solutions Inc, 2018. https://teachonline.ca/sites/default/files/pdfs/vendors_of_elearning_products_dec2018.pdf [Accessed: Sep 2, 2019].

[11] R. Kraleva, M. Sabani, and V. Kralev "An Analysis of Some Learning Management Systems," International Journal on Advanced Science, Engineering and Information Technology, vol. 9, no. 4, pp. 1190-1198, 2019.

[12] G. Tziallas, A. Konogeorgos, and C. Papanastasiou, "An e-learning platform for departmental use," in proc. Of the 2005 WSEAS International Conference on Engineering Education, pp. 326-329, 2005.

[13] M. Ouadoud, M. Y. Chkouri, and A. Nejjari, "Learning management system and the underlying learning theories: towards a new modeling of an LMS," International Journal of Information Science and Technology, vol. 2, no. 1, pp. 25-33, 2018.

[14] R. Kraleva, A. Stoimenovski, D. Kostadinova, and V. Kralev, "Investigating the opportunities of using mobile learning by young children in Bulgaria", International journal of computer science and information security," vol. 14, no. 4, pp. 51-55, 2016.

[15] R. Kraleva, "Designing an Interface For a Mobile Application Based on Children's Opinion," International Journal of Interactive Mobile Technologies, vol. 11, no. 1, pp. 53-70 , 2017.

[16] H. B. Santoso, A. K. Batuparan, R. Y. K. Isal, W. H. Goodridge, "The development of a learning dashboard for lecturers: A case study on a student-centered e-learning environment," The Journal of Educators Online, vol. 15, no. 1, pp. 1-14, 2018.

[17] K. R. Premlatha and T. V. Geetha, "Learning content design and learner adaptation for adaptive e-learning environment: a survey," Artificial Intelligence Review, vol. 44, no. 4, pp. 443-465, 2015.

[18] V. Chang, "Review and discussion: E-learning for academia and industry," International Journal of Information Management, vol. 36, no. 3, pp. 476-485, 2016.

[19] M. Urh, G. Vukovic, and E. Jereb, "The model for introduction of gamification into e-learning in higher education," Procedia-Social and Behavioral Sciences, vol. 197, pp. 388-397, 2015.

[20] T. Kattoua, M. Al-Lozi, and A. A. Alrowwad, "A review of literature on E-learning systems in higher education," International Journal of Business Management \& Economic Research, vol. 7, no. 5, pp. 754-762, 2016.

[21] Y. Aljaraideh and K. Al Bataineh, "Jordanian Students' Barriers of Utilizing Online Learning: A Survey Study," International Education Studies, vol. 12, no. 5, pp. 99-108, 2019.

[22] P. Srivastava, "Advantages \& Disadvantages of E-Education \& E-Learning," Journal of Retail Marketing \& Distribution Management, vol. 2, no. 3, pp. 22-27, 2019.

[23] M. Al-Yahya, R. George, and A. Alfaries, "Ontologies in E-learning: review of the literature," International Journal of Software Engineering and Its Applications, vol. 9, no. 2, pp. 67-84, 2015

[24] M. Abdullah and N. A. A. Ali, "E-learning standards," in proc. of the International Conference on Communication (ICCMIT 2016), pp. 639-648, Nov. 2016.

[25] V. Chang and C. Guetl, "E-learning ecosystem (eles)-a holistic approach for the development of more effective learning environment for small-and-medium sized enterprises (smes)," in proc. of the 2007 Inaugural IEEE-IES Digital EcoSystems and Technologies Conference, IEEE, pp. 420-425, Feb. 2007.

[26] I. Gil-Jaurena, T. Aguado, B. Malik, and P. Cucalón, "E-assessment in a Master online course. A case study".in proc. of the INTED2015, Madrid, pp. 3661-3667, 2015. 
[27] A. Bakhouyi, R. Dehbi, M. Banane, and M. Talea, "A Semantic Web Solution for Enhancing The Interoperability of E-learning Systems by Using Next Generation of SCORM Specifications," International Journal of Emerging Technologies in Learning, vol. 14, no. 11, pp. 174-185, 2019.

[28] A. Bakhouyi, R. Dehbi, M. T. Lti, and O. Hajoui, "Evolution of standardization and interoperability on E-learning systems: An overview," in proc. of the Information Technology Based Higher Education and Training (ITHET) 16th International Conference, pp. 1-8, July 2017.

[29] F. J. Díaz, M. A. Osorio, A. P. Amadeo, and A. Schiavoni, "Standardizing educative content with SCORM: a case study," in proc. of the Society for Information Technology \& Teacher Education International Conference, Association for the Advancement of Computing in Education (AACE), pp. 318-323, March 2006.

[30] L. Lindert and B. Su, "The evolution of scorm to tin can api: implications for instructional design," Educational Technology, vol. 56, no. 4, pp. 44-46, 2016.

[31] K. C. Lim, "Case Studies of xAPI Applications to E-Learning," in proc. of the Twelfth International Conference on eLearning for Knowledge-Based Society, pp. 3-1, 2015.

[32] R. Gurunath and R. A. Kumar, "SaaS explosion leading to a new phase of a learning management system," International Journal of Current Research and Review, vol. 7, no. 22, pp. 62-66, 2015.

[33] L. Giurgiu, "Microlearning an evolving elearning trend," Scientific Bulletin, vol. 22, no. 1, pp. 18-23, 2017.

[34] D. Correa, F. A. Isaza, R. Mazo, \& G. L. Giraldo, "CME-A Web Application Framework Learning Technique Based on Concerns, Micro-Learning and Examples," in proc. of the International Conference on Web Engineering, Springer, Cham, pp. 17-32, June 2018.

[35] S. A. Nikou and A. A. Economides, "Mobile-Based micro-Learning and Assessment: Impact on learning performance and motivation of high school students," Journal of Computer Assisted Learning, vol. 34, no. 3, pp. 269-278, 2018.

[36] L. Caporarello, M. Magni, and F. Pennarola, "One Game Does not Fit All. Gamification and Learning: Overview and Future Directions," in proc. of the Organizing for Digital Innovation, Springer, Cham, pp. 179-188, 2019.

[37] Z. Turan, Z. Avinc, K. Kara, and Y. Goktas, "Gamification and education: Achievements, cognitive loads, and views of students," International Journal of Emerging Technologies in Learning, vol. 11, no. 07, pp. 64-69, 2016.

[38] M. Vesisenaho, M. Juntunen, P. Häkkinen, J. Pöysä-Tarhonen, J. Fagerlund, I. Miakush, and T. Parviainen, "Virtual Reality in Education: Focus on the Role of Emotions and Physiological Reactivity," Journal of Virtual Worlds Research, vol. 12, no. 1, 2019.

[39] J. Martín-Gutiérrez, C. E. Mora, B. Añorbe-Díaz, and A. González-Marrero, "Virtual technologies trends in education," EURASIA Journal of Mathematics Science and Technology Education, vol. 13, no. 2, pp. 469-486, 2017.

[40] N. G. Canbek and M. E. Mutlu, "On the track of artificial intelligence: Learning with intelligent personal assistants," Journal of Human Sciences, vol. 13, no. 1, pp. 592-601, 2016.

[41] X. L. Pham, T. Pham, Q. M. Nguyen, T. H. Nguyen, T. T. H. Cao, "Chatbot as an Intelligent Personal Assistant for Mobile Language Learning," in proc. of the 2018 2nd International Conference on Education and E-Learning, ACM, pp. 16-21, November 2018.

[42] Z. V. Sandoval, "Design and implementation of a chatbot in online higher education settings," Issues in Information Systems, vol. 19, no. 4, 2018.

[43] S. Sfenrianto, Y. B. Hartarto, H. Akbar, M. Mukhtar, E. Efriadi, and M. Wahyudi, (2018). "An Adaptive Learning System based on Knowledge Level for English Learning," International Journal of Emerging Technologies in Learning, vol. 13, no. 12, pp. 191-200, 2018.

[44] F. I. Sapundzhi, M. S. Popstoilov, (2018) "Optimization algorithms for finding the shortest paths," Bulgarian Chemical Communications, vol. 50 (Special Issue B), pp. 115-120, 2018.

[45] H. M. Truong, "Integrating learning styles and adaptive e-learning system: Current developments, problems and opportunities," Computers in human behavior, vol. 55, pp. 1185-1193, 2016.

[46] D. Zhang, J. F. Nunamaker, "Powering e-learning in the new millennium: an overview of e-learning and enabling technology," Information systems frontiers, vol. 5, no. 2, pp. 207-218, 2003.

[47] J. K. Wong, O. T. Oladinrin, C. M. Ho, E. Guilbert, and R. Kam, "Assessment of video-based e-learning in a construction measurement course," International Journal of Construction Management, pp. 1-7, 2018.

[48] M. I. Eid and I. M. Al-Jabri, "Social networking, knowledge sharing, and student learning: The case of university students," Computers \& Education, vol. 99, pp. 14-27, 2016.

[49] E. Mnkandla and A. Minnaar, "The Use of Social Media in E-Learning: A Metasynthesis," The International Review of Research in Open and Distributed Learning, vol. 18, no. 5, 2017.

[50] V. Kralev, R. Kraleva, and N. Siniagina, "An integrated system for university course timetabling," in proc. Of the Third international scientific conference - FMNS2009, vol. 1, pp. 99-105, 2009. 


\section{BIOGRAPHIES OF AUTHORS}
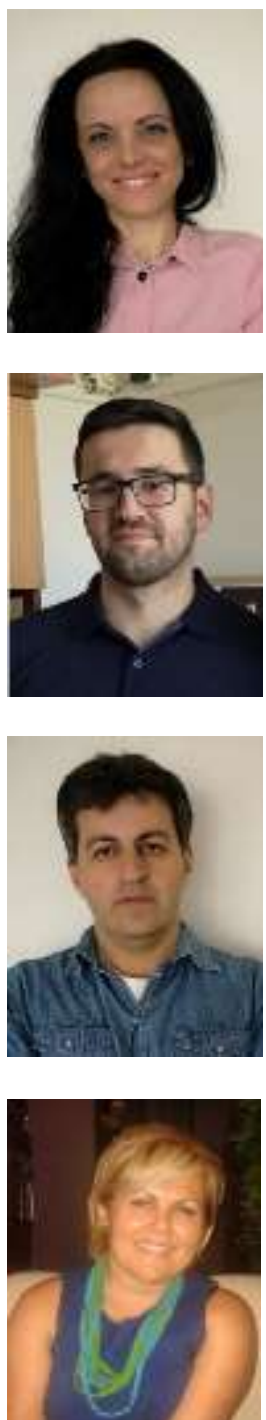

Radoslava Kraleva is an assistant professor of Computer Science at the Faculty of Mathematics and Natural Sciences, South-West University "Neofit Rilski", Blagoevgrad, Bulgaria. She defended her PhD Thesis "Acoustic-Phonetic Modeling for Children's Speech Recognition in Bulgarian" in 2014. Her research interests include child-computer interaction, speech recognition, mobile app development and computer graphic. She is an editorial board member of the "International Journal of Advanced Computer Research" and of the journal "Perspectives of Innovations, Economics and Business". She is a reviewer of iJET, "International Journal on Advanced Science, Engineering and Information Technology", "Computer Standards \& Interfaces", and many others.

Mehrudin Sabani received his BSc of Computer Science at Department of Informatics, in South-West University "Neofit Rilski", Blagoevgrad, Bulgaria.

His research interests include e-learning, mobile learning, e-learning management systems, web development.

Velin Kralev is an assistant professor of Computer Science at the Faculty of Mathematics and Natural Sciences, South-West University "Neofit Rilski", Blagoevgrad, Bulgaria. He defended his $\mathrm{PhD}$ Thesis in 2010. His research interests include database systems development, optimization problems of the scheduling theory, graph theory and component-oriented software engineering. He is an editorial board member of the International Journal of Advanced Computer Research (IJACR).

Dafina Kostadinova is currently an Associate Professor at the Department of Germanic and Romance Studies at the Faculty of Philology of the South-West University "Neofit Rilski" since 2000. She has taught General English, Business English, Translation, Specialized Translation, Contrastive Analysis, Academic Writing, and Introduction into General Linguistics to students from the Faculty of Philology, the Faculty of Economics and the Faculty of Pedagogy. In 2012 Kostadinova defended her Ph.D. Thesis Structural Interferences in the Production of English by Bulgarians. She co-authored a textbook called Specialized Translation (Selected English and Bulgarian Texts for Translation) published in 2015. She is a member of the Editorial Board of the journal 'Orbis Linguarum' issued at the SWU "Neofit Rilski". 